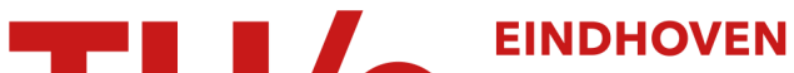 UNIVERSITY OF TECHNOLOGY
}

\section{Cathodic reduction of oxygen at new iron complexes}

Citation for published version (APA):

Elmorsi, M. A., Gabor, M., \& Barendrecht, E. (1991). Cathodic reduction of oxygen at new iron complexes. Journal of Applied Electrochemistry, 21(11), 1005-1012. https://doi.org/10.1007/BF01077587

DOI:

10.1007/BF01077587

Document status and date:

Published: 01/01/1991

\section{Document Version:}

Publisher's PDF, also known as Version of Record (includes final page, issue and volume numbers)

\section{Please check the document version of this publication:}

- A submitted manuscript is the version of the article upon submission and before peer-review. There can be important differences between the submitted version and the official published version of record. People interested in the research are advised to contact the author for the final version of the publication, or visit the $\mathrm{DOI}$ to the publisher's website.

- The final author version and the galley proof are versions of the publication after peer review.

- The final published version features the final layout of the paper including the volume, issue and page numbers.

Link to publication

\section{General rights}

Copyright and moral rights for the publications made accessible in the public portal are retained by the authors and/or other copyright owners and it is a condition of accessing publications that users recognise and abide by the legal requirements associated with these rights.

- Users may download and print one copy of any publication from the public portal for the purpose of private study or research.

- You may not further distribute the material or use it for any profit-making activity or commercial gain

- You may freely distribute the URL identifying the publication in the public portal.

If the publication is distributed under the terms of Article $25 \mathrm{fa}$ of the Dutch Copyright Act, indicated by the "Taverne" license above, please follow below link for the End User Agreement:

www.tue.nl/taverne

\section{Take down policy}

If you believe that this document breaches copyright please contact us at:

openaccess@tue.nl

providing details and we will investigate your claim. 


\title{
Cathodic reduction of oxygen at new iron complexes
}

\author{
M. A. ELMORSI*, M. GABOR \\ Chemistry Department, Faculty of Science, Tanta University, Tanta, Egypt \\ E. BARENDRECHT \\ Laboratory for Electrochemistry, Faculty of Chemical Technology, Eindhoven University of Technology, \\ The Netherlands
}

Received 19 September 1990; revised 28 February 1991

The redox behaviour of some new iron complexes has been studied in both acidic and alkaline solutions. The complexes were adsorbed irreversibly at the pyrolytic graphite disc of a rotating ring(Pt)-disc electrode (RRDE) from a $10^{-3} \mathrm{M}$ solution of the complex in $\mathrm{N}, \mathrm{N}$-dimethylformamide (DMF). Moreover, the electrocatalytic properties of these complexes for the cathodic reduction of oxygen were investigated. Both the redox behaviour and the electrocatalytic effect are discussed in relation to the medium composition as well as the molecular structure of the complex.

\section{Introduction}

The electrocatalysis of oxygen reduction with transitionmetal chelates has been studied by many authors [1-10], mostly in relation to energy conversion systems (fuel cells, metal-air batteries) and some industrial applications. These transition-metal complexes can be attached to electrode surfaces, an attractive approach for theoretical studies being the irreversible adsorption of the complex onto pyrolytic graphite. Electrocatalytic activities with the $\mathrm{N}_{4}$-chelates of $\mathrm{Fe}$ and $\mathrm{Co}$ for $\mathrm{O}_{2}$-reduction are reported [11].

For most transition-metal complexes a probable structure for oxygen bonding is the end-on interaction as proposed by Pauling [12]. The $\sigma$-bonding can occur through the transfer of a metal $\mathrm{d}_{\mathrm{z}}^{2}$-electron to the $\pi^{*}$. antibonding oxygen molecular orbital with possible retrodative bonding from oxygen $\pi$-orbitals to metal d-orbitals $[13,14]$. The square pyramidal complexes of $\mathrm{Fe}(\mathrm{II})$ and $\mathrm{Co}$ (II), which show an attractive activity for oxygen reduction, involve such an end-on interaction [15]. The adsorption of oxygen on the square pyramidal complexes of $\mathrm{Fe}$ (II) and $\mathrm{Co}(\mathrm{II})$, may lead directly to the superoxide state. It has been proposed also that oxygen binding to $\mathrm{Fe}$ involves $\mathrm{O}^{-}$-or $\mathrm{O}^{2-}$ states with $\mathrm{Fe}$ in the III-valent state $[16,17]$. It was also shown that mononuclear $\mathrm{Co}$ chelates reduce $\mathrm{O}_{2}$ to $\mathrm{H}_{2} \mathrm{O}_{2}$; however, with $\mathrm{Fe}$ as the central metal ion, the reduction of $\mathrm{O}_{2}$ to $\mathrm{H}_{2} \mathrm{O}_{2}$ was predominant [11]. Collman et al. [18-20] have reported the reduction of $\mathrm{O}_{2}$ to $\mathrm{H}_{2} \mathrm{O}_{2}$ on cofacial dicobaltporphyrins. On the other hand, 4e-reduction of oxygen on planar cobalt complexes was also reported by Yeager and Sarangapani [21].

In the present investigation we report results with different Fe complexes, and discuss some correlations between the redox characteristics, electrocatalytic properties and the molecular structure of the complexes.

\section{Experimental details}

The electrochemical measurements were performed using a rotating ring $(\mathrm{Pt})$-pyrolytic graphite $(\mathrm{Cp})$ disc electrode $\left(A=0.50 \mathrm{~cm}^{2}, N=0.242\right)$, in a standard three-compartment electrochemical cell, filled with $150 \mathrm{ml}$ electrolyte solution $\left(0.05 \mathrm{M} \mathrm{H}_{2} \mathrm{SO}_{4}\right.$ or $0.1 \mathrm{M}$ $\mathrm{KOH}$ ), either nitrogen or oxygen saturated. The redox behaviour of the seven complexes investigated (see Table 1) were measured cyclovoltammetrically at various sweep rates $\left(50-300 \mathrm{mV} \mathrm{s}^{-1}\right)$ in the absence of oxygen. The oxygen reduction was measured by scanning the disc potential from 1000 to $0 \mathrm{mV} /$ RHE with $50 \mathrm{mV} \mathrm{s}^{-1}$ at various rotation frequencies $\left(4-64 \mathrm{~s}^{-1}\right)$ of the RRDE. The ring was slightly platinized to ensure quantitative $\mathrm{H}_{2} \mathrm{O}_{2}$ detection; its potential was set at $1200 \mathrm{mV} /$ RHE. Before measurements, the ring was activated by periodic evolution of hydrogen and oxygen for $\sim 1 \mathrm{~min}$. The catalyst was applied to the disc (previously polished with $0.3 \mu \mathrm{m} \mathrm{Al}_{2} \mathrm{O}_{3}$ solution, Buehler, then washed several times with distilled water) via irreversible adsorption from a $10^{-3} \mathrm{M}$ solution of the complex in DMF. An adsorption time of 30 min was used in all experiments. The temperature was kept at $(293 \pm 1) \mathrm{K}$. A bipotentiostat type BI-Pad Tacussel coupled with a voltage scan generator, Wenking model VSG 72, was used for these measurements and the data were recorded using a Hewlett Packard 7046A $\mathrm{X}-\mathrm{Y}$ recorder.

\section{Results}

\subsection{Redox behaviour of the complexes in $\mathrm{O}_{2}$-free solutions}

The cyclic voltammetric (CV) data of the seven $\mathrm{Fe}$ complexes in $0.05 \mathrm{M} \mathrm{H}_{2} \mathrm{SO}_{4}$ and in $0.1 \mathrm{M} \mathrm{KOH}$ are given in Table 2 . The recorded cyclic voltammograms

* Chemistry Department, Faculty of Education, Sakaka El Jouf P.O. Box 269, Saudi Arabia. 
Table 1. Structural formulae of the seven investigated iron organic complexes.
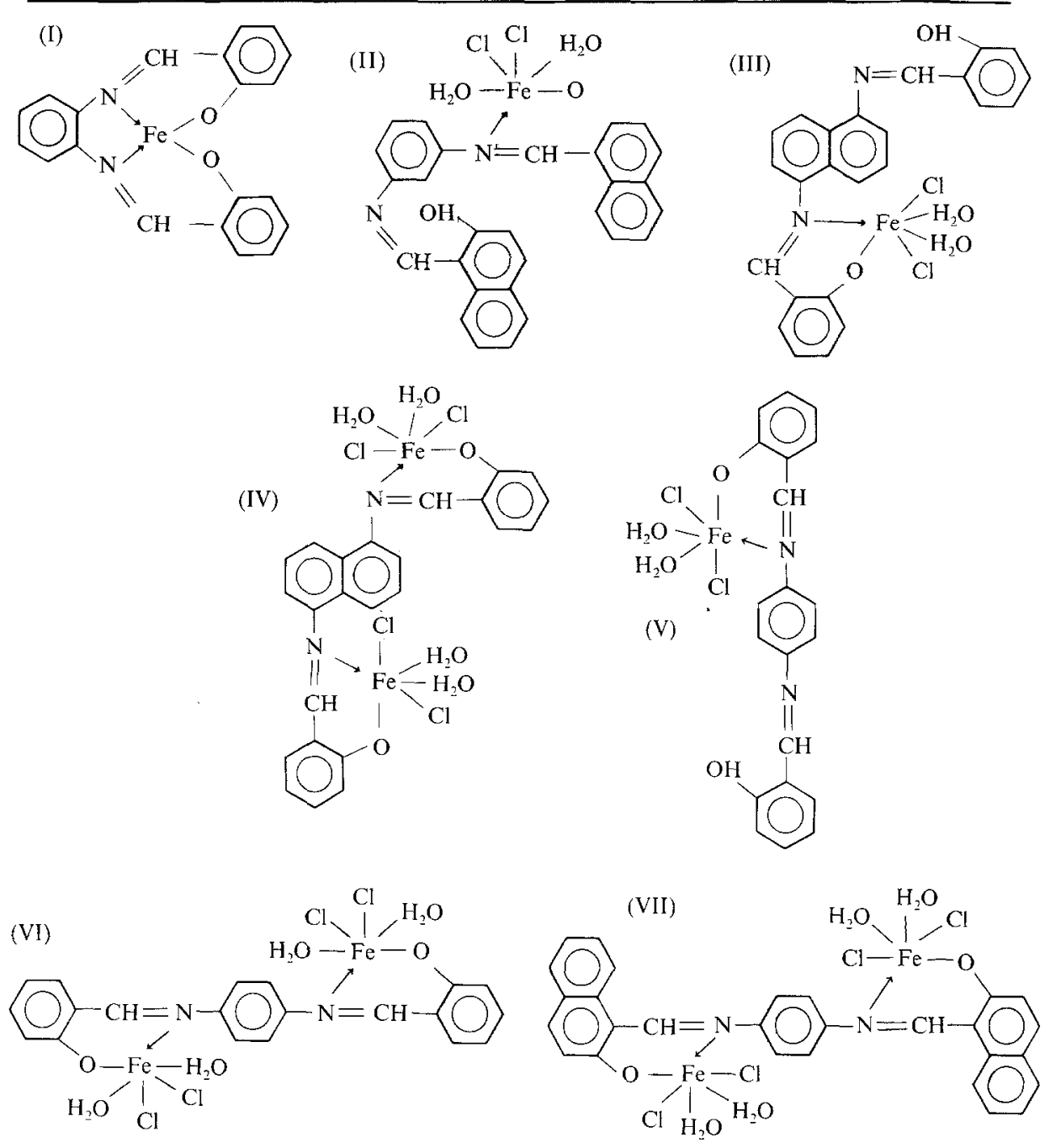

of the complexes are shown in Fig. 1, both in acid and in alkaline solutions.

Complex I. For this Fe-complex, characterized by the bonding system $\mathrm{Fe}, 2 \mathrm{~N}, 2 \mathrm{O}$, two characteristic redox peaks were observed, both in acid and in alkaline solutions (Fig. 1.I). In acid solutions, however, the first oxidation peak is scarcely developed and more or less masked by the second peak; the first reduction peak is, however, clearly developed. Moreover, the degree of reversibility of these redox processes in acid and alkaline solutions can be derived from $\Delta E_{\mathrm{p}}$ values (where $\Delta E_{\mathrm{p}}=\Delta E_{\mathrm{p}}$ "ox" $-\Delta E_{\mathrm{p}}$ "red"). The $\Delta E_{\mathrm{p}}$ (red)-value for the first redox process is practically $\mathrm{pH}$-independent, while the second peak shifts roughly $-7.5 \mathrm{mV} / \mathrm{pH}$ unit.

Complex II. The CV-data of the Fe-complex (II) show that the first redox peak is composed by several overlapping peaks, both in acid and in alkaline solutions (Fig. 1.II). The main peak is nearly pH-independent, both in $E_{\mathrm{p}}$ and in height. In the more anodic domain other overlapping peaks occur. At higher sweep rates the broad reduction peak in alkaline medium splits into at least two characteristic peaks, prob- ably indicating the existence of more than one adsorption state of the same oxidation state of Fe. The redox processes of this Fe-complex in both acidic and alkaline solutions are evidently reversible. Also in this case, the cyclic voltammetric data show no sweep rate dependency of $E_{\mathrm{p}}$ and as expected for reversible behaviour, $i_{\mathrm{p}}$ is proportional to the potential scan rate.

Complex III. This Fe-complex is also characterized by the group $\mathrm{Fe}, \mathrm{N}, \mathrm{O}$. The redox behaviour of this compound in both acidic and alkaline medium is shown in Fig. 1c. In these solutions two broad oxidation peaks are observed in the potential range from $100-600 \mathrm{mV}$ (see also Table 2.III).

At higher sweep rates, i.e. $V \geqslant 100 \mathrm{mV} \mathrm{s}^{-1}$, these broad peaks become better defined. The potential difference between the oxidation and the reduction peak is about $100 \mathrm{mV}$ (for both redox processes). In alkaline solutions the first redox process is rather masked and the peaks of the second redox process are very broad: the potential difference of these peaks is about $80 \mathrm{mV}$. Moreover, the second redox process is slightly shifted to more positive values and even so is the first redox process shifted to more negative values, 


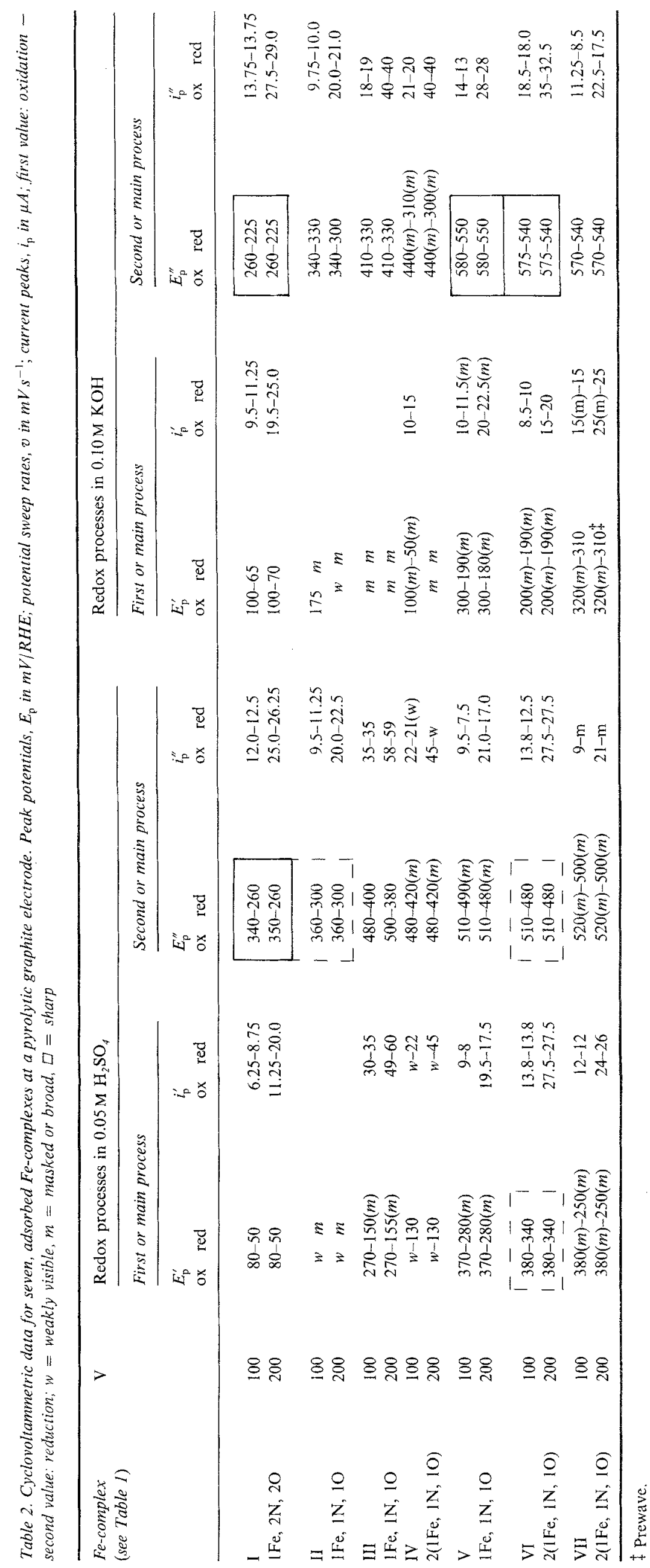



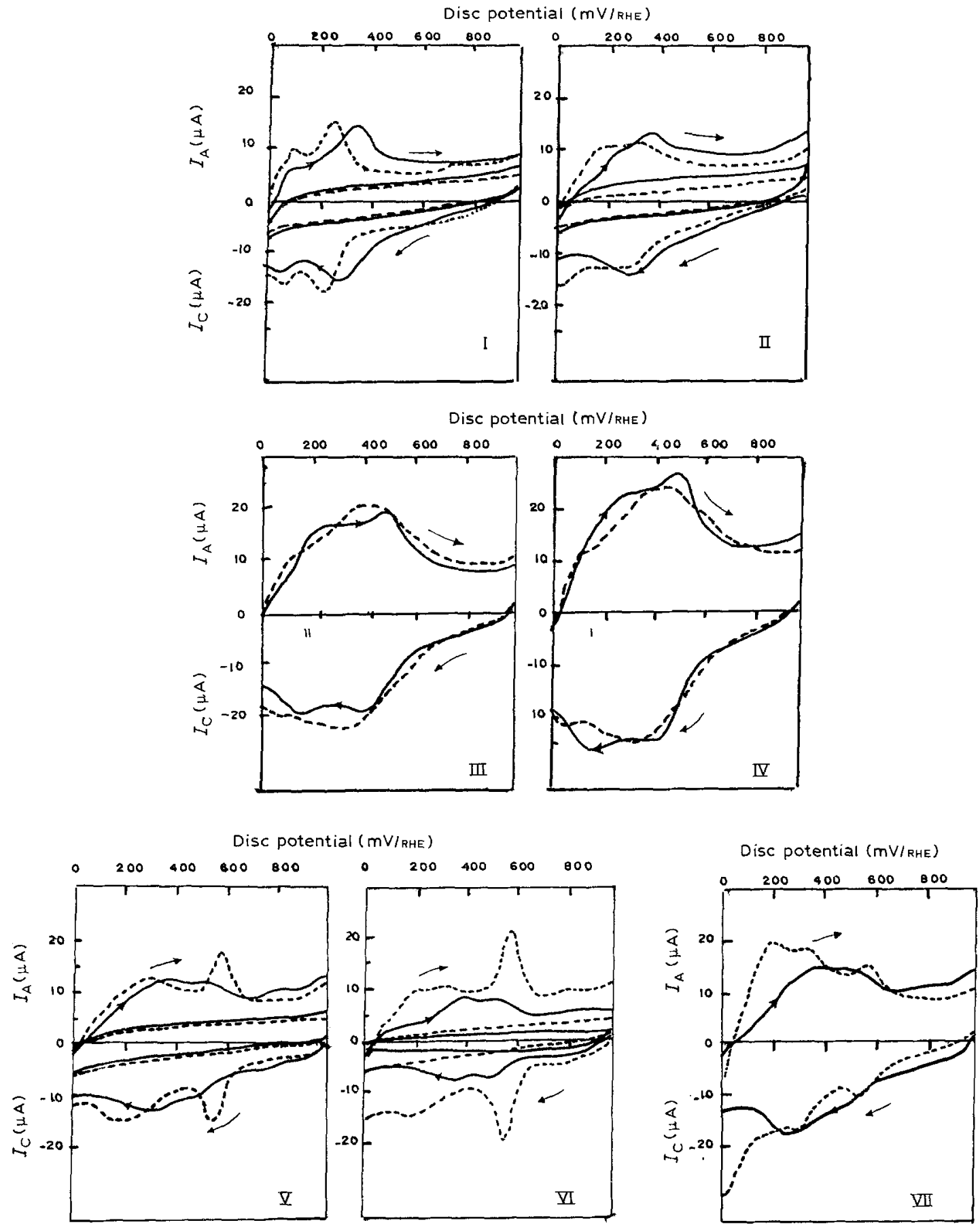

Fig. 1. Cyclovoltammograms of seven Fe-complexes (see Table 1) in $0.05 \mathrm{M} \mathrm{H}_{2} \mathrm{SO}_{4}(-)$ and in $0.1 \mathrm{M} \mathrm{KOH} \mathrm{(--} \mathrm{),} \mathrm{with} \mathrm{the} \mathrm{base} \mathrm{lines}$ for I, II, V and VI. Potential sweep rate: $100 \mathrm{mV} \mathrm{s}^{-1}$. $I_{\mathrm{C}}$ cathodic current, $I_{\mathrm{A}}$, anodic current.

compared with the corresponding values for complex I and II.

Complex $I V$. The redox behaviour of this Fe-complex, both in acid and alkaline medium, is shown in Fig. 1.IV and tabulated in Table 2.IV. It is interesting to note that this compound contains two Fe centres and that each centre is of $F e, N, O$ system. The redox behaviour in both the acid and the alkaline solution is more or less similar to that of complex III. In acid solution the two redox processes are better separated, especially at higher sweep rates. It is clear from Fig. 1.IV that in alkaline solutions only the second redox process is less masked.
Complex $V$. For this complex (See Fig. 1.V and Table 2.V) and in acid solution, and at higher sweep rates, e.g. $v \geqslant 150 \mathrm{mV} \mathrm{s}^{-1}$, a third redox process becomes visible, pointing to a more complex valence state behaviour. In $0.1 \mathrm{M} \mathrm{KOH}$ solution, the first redox process shows broad peaks, while the second process is very well-defined.

Complex VI. The CV profiles of this complex, both in acid and alkaline solutions, are shown in Fig. 1.VI. Concerning the molecular structure, this complex contains two Fe centres, as complex IV, however with a different ligand structure (see Table 1). Nevertheless, its behaviour is more or less similar to that of complex 
$\mathrm{V}$ either in acid or alkaline solution. The stability of this adsorbed complex was tested in the acid medium: the electrode was left overnight $(\sim 20 \mathrm{~h})$ in $0.05 \mathrm{M}$ $\mathrm{H}_{2} \mathrm{SO}_{4}$; solution; then the cyclic voltammograms were recorded. A similar redox behaviour as earlier was observed, but the redox peaks were shifted to more positive values by about $40 \mathrm{mV} / \mathrm{RHE}$.

Complex VII. The cyclic voltammograms of this complex, (which also contains two iron centres but naphthyl moieties) in $0.05 \mathrm{M} \mathrm{H}_{2} \mathrm{SO}_{4}$ and in $0.1 \mathrm{M} \mathrm{KOH}$ solutions, are shown in Fig. 1.VII. In acid medium the voltammograms are characterized by broad and masked redox peaks with more pronounced peaks at higher sweep rates. At more positive potentials $(\sim 800 \mathrm{mV})$ other oxidation states of the complex (not only the central Fe but also the organic part) become apparent. In the alkaline solution, however, the illdefined spectrum observed in the acid medium, is divided into at least two well-defined peaks.

\subsection{Results: oxygen reduction as studied at the RRDE}

All the Fe-complex catalysts were applied onto a polished $\left(0.3 \mu \mathrm{m} \mathrm{Al}_{2} \mathrm{O}_{3}\right.$ Buehler $) \mathrm{Cp} \operatorname{disc}\left(A=0.50 \mathrm{~cm}^{2}\right)$ via irreversible adsorption for $30 \mathrm{~min}$ from a $10^{-3} \mathrm{M}$ N,N-DMF solution. The molecular structure of the complexes used are shown in Table 1. These complexes differ as to whether they contain one or two iron centres and/or in the type of the ligand surrounding the metal centre. The measurements are carried out with a RRDE and the water solutions were oxygen-saturated at room temperature.

3.2.1. $\mathrm{O}_{2}$-reduction in alkaline solution $(0.1 \mathrm{M} \mathrm{KOH})$. The results for the oxygen-reduction at the iron complexes in $0.1 \mathrm{M} \mathrm{KOH}$ solution are shown in Fig. 2; the

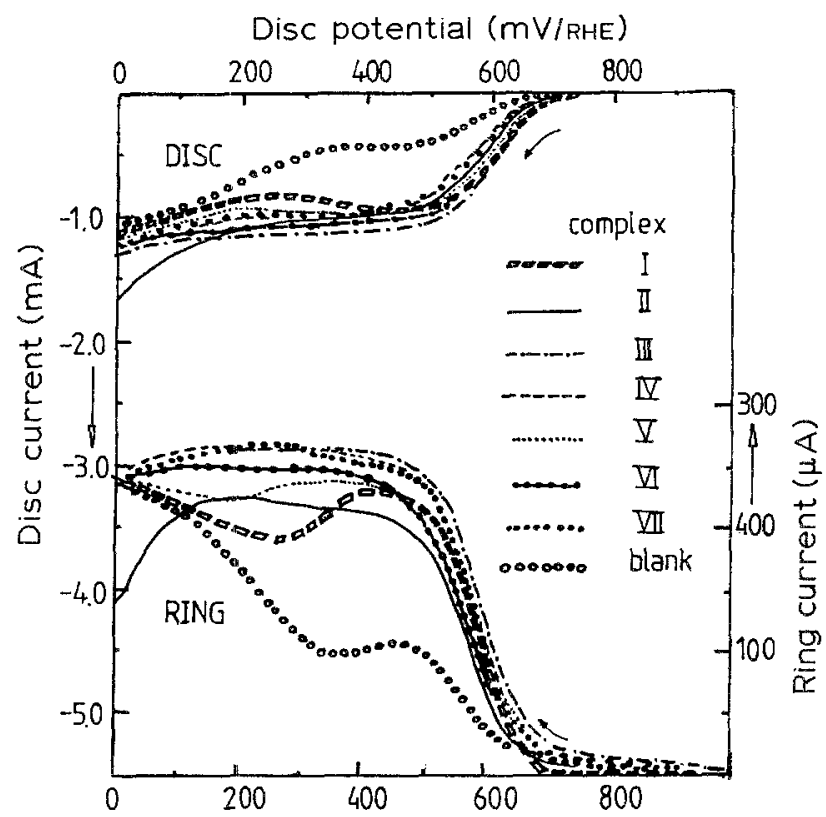

Fig. 2. Oxygen reduction as studied at the RRDE in $0.1 \mathrm{M} \mathrm{KOH}$; $I_{0}=$ disc current, $I_{\mathrm{R}}=$ ring current at $1.2 \mathrm{~V} / \mathrm{RHE}$. Potential sweep rate: $50 \mathrm{mV} \mathrm{s}^{-1}$, rotation frequency: $16 \mathrm{~s}^{-1}$. blank (only the prepolished Cp surface) is also shown in Fig. 2. In all cases the potential sweep rate was $50 \mathrm{mVs}^{-1}$ and the rotation frequency $16 \mathrm{~s}^{-1}$.

The oxygen-reduction at a $\mathrm{Cp}$ electrode in $0.1 \mathrm{M}$ $\mathrm{KOH}$ solution starts at $\sim 700 \mathrm{mV} / \mathrm{RHE}$.

Complex 1 . The oxygen-reduction behaviour at this Fe-complex is shown in Fig. $2(---)$. Comparing this with that at the substrate $(\mathrm{Cp})$ only, it is clear that the reduction potential is shifted only some $50-100 \mathrm{mV}$ in the positive direction. However, the limiring current values for both the disc and the ring are now more than double. The results for the other complexes do not show much difference compared to those obtained for complex I, neither in potential, nor in current. In all cases the reduction is mass-transport limited as can be deduced from the values of the limiting current at different rotation frequencies $\left(4,16,36\right.$ and $\left.64 \mathrm{~s}^{-1}\right)$. A stability test was carried out with complex (IV) in $\mathrm{KOH}$ solution by repeating the oxygen-reduction measurements as well as the $\mathrm{CV}$ profile $\sim 18 \mathrm{~h}$ after the first measurement: no remarkable change in behaviour was recorded.

Generally, for all these complexes the oxygenreduction in $0.1 \mathrm{M} \mathrm{KOH}$ solution occurs at about $750 \mathrm{mV} / \mathrm{RHE}$. The final reduction product of $\mathrm{O}_{2}$ under these conditions is mainly $\mathrm{H}_{2} \mathrm{O}_{2}$, as can be concluded from the ratio of the disc and ring current values. It is intesting to note that the oxygen-reduction behaviour at the cobalt tetrasulphonato $P$ hthalocyanine (CoTs-Pc) catalysts, studied by several authors, shows a similar behaviour. However, the stability for $(\mathrm{CoTsPc})$ is less than that for the Fe-complexes, studied here.

3.2.2. $\mathrm{O}_{2}$-reduction in acid medium $\left(0.05 \mathrm{M} \mathrm{H}_{2} \mathrm{SO}_{4}\right)$. The behaviour of oxygen-reduction at the $\mathrm{Fe}$-complexes I, II, III, V, and VII, in $0.05 \mathrm{M} \mathrm{H}_{2} \mathrm{SO}_{4}$ solution is shown in Fig. 2b. Both the disc and ring currents are decreased compared to alkaline solutions (Fig. 2), which can be explained by a partial deactivation of the catalytically active sites in acid solution. It is clear from the ratio of the ring and disc currents that no change in the oxygen-reduction mechanism occurs compared to the alkaline solution.

In fact in $0.05 \mathrm{M} \mathrm{H}_{2} \mathrm{SO}_{4}$ solution, the reduction current shows no typical rotation frequency dependence which indicates that the reduction process is not purely diffusion controlled. Moreover, the reduction process of oxygen in the presence of the Fe-complex at the disc starts at $\sim 800 \mathrm{mV} / \mathrm{RHE}$ and it is mainly kinetically limited.

On the other hand, the oxygen-reduction current as well as the catalytic activity of the Fe-complexes under investigation are found to increase with time in $0.05 \mathrm{M} \mathrm{H}_{2} \mathrm{SO}_{4}$ solution. Also, a positive electrocatalytic effect of the adsorbed Fe-complexes towards the $\mathrm{O}_{2}$-reduction to $\mathrm{H}_{2} \mathrm{O}$ exclusively may be obtained as a result of dipping the adsorbed catalysts in the platinizing solution, probably such behaviour is caused by increasing the number of active sites at the disc surface 


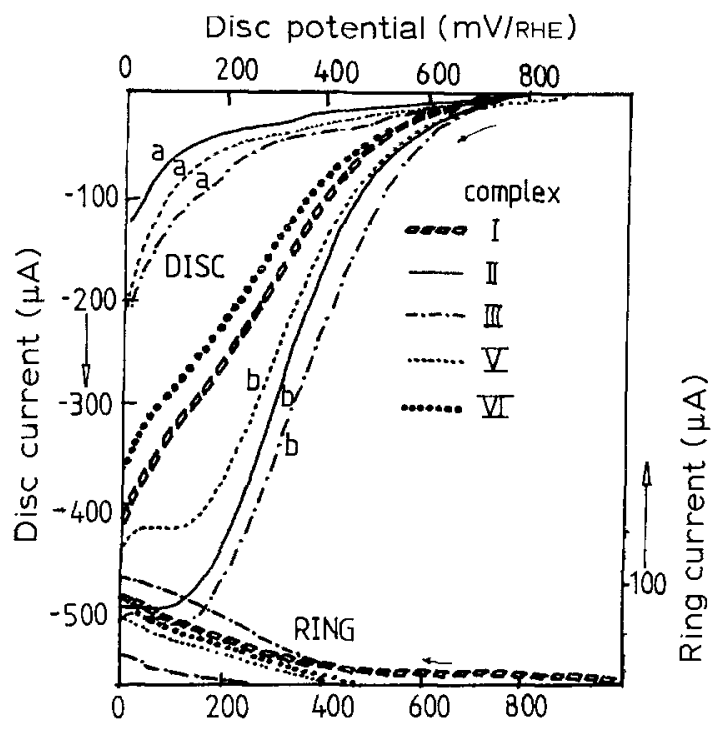

Fig. 3. Oxygen reduction as studied at the RRDE in $0.05 \mathrm{M} \mathrm{H}_{2} \mathrm{SO}_{4}$; $I_{\mathrm{D}}=$ disc current, $I_{\mathrm{R}}=$ ring current at $1.2 \mathrm{~V} / \mathrm{RHE}$. The complexes II, III and $\mathrm{V}$ are recorded without (a) and with exposure to a platinizing solution for $30 \mathrm{~min}$ (b). Potential sweep rate: $50 \mathrm{mV} \mathrm{s}^{-1}$, rotation frequency: $16 \mathrm{~s}^{-1}$.

via Pt-adsorption or through ion-exchange of some Fe-centres with Pt-ions.

Such improvement of the modified surface to oxygen-reduction is observed only in $0.05 \mathrm{M} \mathrm{H}_{2} \mathrm{SO}_{4}$ solution (see the behaviour of the complexes II, III and $\mathrm{V}$, time of exposure $30 \mathrm{~min}$. See Fig. 3).

\section{General discussion}

\subsection{General discussion of the redox behaviour of the $\mathrm{Fe}$-complexes in $\mathrm{O}_{2}$-free solutions}

The cyclovoltammograms of the different adsorbed Fe-complexes in $0.05 \mathrm{M} \mathrm{H}_{2} \mathrm{SO}_{4}$ and in $0.1 \mathrm{M} \mathrm{KOH}$ solutions are given in Fig. 1. Compared to the $C p$ background, the adsorbed molecules give rise to one or more redox peaks. In the case of a reversible electron transfer to the adsorbed species, the redox potential is equal to the peak potential and the peak area proportional to the catalyst loading.

The assignment of the different redox peaks to the valence states is not completely straightforward. The redox peaks observed at the higher potentials are probably due to the $\mathrm{Fe}^{\mathrm{II}} / \mathrm{Fe}^{\mathrm{III}}$-redox couple; even so, the redox peaks at the lower potential values can most probably be related to the $\mathrm{Fe}^{\mathrm{l}} / \mathrm{Fe}^{\mathrm{II}}$-redox couple. The difference in the redox behaviour, on going from alkaline to acidic medium, must partly be attributed to the protonation of the $\mathrm{N}=\mathrm{CH}$ group. The redox behaviour as such is highly influenced by the molecular structure of the complex, i.e. by the ligands surrounding the central metal atom $(\mathrm{Fe})$, and whether the complex contains one or two $\mathrm{Fe}$-centres. The redox behaviour of the iron-tetrasulphonato-phthalocyanine ( $\mathrm{FeTsPc}$ ) complexes at higher potential is due to the $\mathrm{Fe}$ (III)-TsPc couple [7], with the redox reaction:

$$
\mathrm{Fe}^{(\mathrm{III})} \mathrm{OH}+\mathrm{H}_{2} \mathrm{O}+e^{-} \rightleftharpoons \mathrm{Fe}^{(\mathrm{II})} \mathrm{OH}_{2}+\mathrm{OH}^{-}
$$

On the other hand, the peak observed at lower potential values was believed to be due to some reduced form, caused by electron delocalization in the $\pi$-system of the ligand or, alternatively, with the $\mathrm{Fe}$ in the I-state.

\subsection{General discussion on the cathodic $\mathrm{O}_{2}$-reduction at the Fe-complexes}

The results of the oxygen-reduction experiments are depicted in Figs 2 and 3 (alkaline and acid solutions, respectively).

Oxygen reduction is considered to proceed by two pathways $[22,23]$ :

(i) Direct 4-electron pathway

In acid solutions:

$$
\begin{aligned}
\mathrm{O}_{2}+4 \mathrm{H}^{+}+4 e^{-} \longrightarrow 2 \mathrm{H}_{2} \mathrm{O} ; \quad E^{0} & =1.229 \mathrm{~V} \\
\mathrm{pH} & =0
\end{aligned}
$$

In alkaline solutions:

$$
\begin{aligned}
\mathrm{O}_{2}+2 \mathrm{H}_{2} \mathrm{O}+4 e^{-} \longrightarrow 4 \mathrm{OH}^{-} ; \quad E^{0} & =0.401 \mathrm{~V} \\
\mathrm{pH} & =14
\end{aligned}
$$

(ii) Peroxide pathway

In acid solutions:

$$
\begin{aligned}
\mathrm{O}_{2}+2 \mathrm{H}^{+}+2 e^{-} \longrightarrow \mathrm{H}_{2} \mathrm{O}_{2} ; \quad E^{0} & =0.67 \mathrm{~V} \\
\mathrm{pH} & =0
\end{aligned}
$$

followed by either:

$$
\mathrm{H}_{2} \mathrm{O}_{2}+2 \mathrm{H}^{+}+2 e^{-} \longrightarrow 2 \mathrm{H}_{2} \mathrm{O} ; \quad E^{0}=1.77 \mathrm{~V}
$$

Or

$$
2 \mathrm{H}_{2} \mathrm{O}_{2} \longrightarrow 2 \mathrm{H}_{2} \mathrm{O}+\mathrm{O}_{2}
$$

In alkaline solutions:

$$
\begin{aligned}
\mathrm{O}_{2}+\mathrm{H}_{2} \mathrm{O}+2 e^{-} & \longrightarrow \mathrm{HO}_{2}^{-}+\mathrm{OH}^{-} ; \\
E^{0} & =0.065 \mathrm{~V} \\
\mathrm{pH} & =14
\end{aligned}
$$

followed by either:

$$
\begin{gathered}
\mathrm{HO}_{2}^{-}+\mathrm{H}_{2} \mathrm{O}+2 e^{-} \longrightarrow 3 \mathrm{OH}^{-} \\
E^{0}=+0.867 \mathrm{~V}
\end{gathered}
$$

Or

$$
2 \mathrm{HO}_{2}^{-} \longrightarrow 2 \mathrm{OH}^{-}+\mathrm{O}_{2}
$$

(for these reactions the potential values are given with respect to the normal hydrogen electrode (NHE) at $25^{\circ} \mathrm{C}$ ).

The cathodic reduction of oxygen in alkaline solutions (Fig. 2a) indicates a pure diffusion controlled 4-electron reduction process, i.e. the peroxide path- 
way is followed. Fig. 2, shows though not clearly, a first wave and the start of a second wave. The first wave may correspond to the reduction of $\mathrm{O}_{2}$ to $\mathrm{HO}_{2}^{-}$ according to Reaction 6 , while the second is attributed to the further reduction of $\mathrm{HO}_{2}^{-}$to $\mathrm{OH}^{-}$as given in Reaction 7.

In acid solutions both disc and ring current values are decreased compared to alkaline solutions. This may be explained by a partial deactivation of the catalytically active sites in acid solutions.

Another interpretation of such results may be offered by the assumption of specific adsorption of oxygen at different active sites followed by the transfer of the first electron as a rate determining step. For example,

$$
\mathrm{O}_{2}+\mathrm{H}^{+}+e^{-} \longrightarrow \mathrm{HO}_{2}
$$

On the other hand, the dependence of the ring current on the disc potential might signify an influence on the $\mathrm{O}_{2}^{-}$adsorption by water dipoles. Generally, in $0.05 \mathrm{M} \mathrm{H}_{2} \mathrm{SO}_{4}$ (Fig. 3), the reduction is kinetically limited at low overpotentials, while at higher overpotentials, the current is clearly diffusion limited and the reduction also proceeds to $\mathrm{H}_{2} \mathrm{O}$.

The formation of dimeric $\mu$-peroxo oxygen adducts on iron containing chelates has been well documented [24]. Since it is most likely that the adsorbed molecules lie parallel to the surface, these dimeric species are few in number, for formation of these dimeric species demands considerable surface mobility, because of the required $0.4 \mathrm{~nm}$ spacing. It is clear from the results in the acidic solutions that we may have monomeric and dimeric $\mathrm{O}_{2}$-adducts. At low overpotentials only the dimers are able to reduce dioxygen, but at high overpotential the monomers start to reduce $\mathrm{O}_{2}$ and some $\mathrm{H}_{2} \mathrm{O}_{2}$ as an intermediate product, is also formed.

It may be stated that, the reduction behaviour of oxygen at the $\mathrm{Fe}$-complexes studied is mainly medium dependent, while the molecular structure of the complex has hardly any influence.

It is noticed that the $E_{1 / 2}$-values are shifted in the anodic direction by repeated scanning in $0.05 \mathrm{M}$ $\mathrm{H}_{2} \mathrm{SO}_{4}$ solution (Fig. 3), i.e. the activity of the catalyst increases by creating more active sites, particularly when the RRDE is pretreated in the platinizing solution. Even so, the reduction current increased (at constant rotation frequency). In order to clarify such a phenomenon a series of experiments were performed without the catalyst as well as with different catalysts. It was concluded that, the behaviour obtained with the Fe-complexes studied, pretreated in the platinized solution and in $0.05 \mathrm{M} \mathrm{H}_{2} \mathrm{SO}_{4}$ solution, may indicate the increase of active sites with time which modify the surface. Such surface modification may be obtained either via Pt-adsorption or the ion exchange of Fe-atoms for Pt-centres in the complex, which are catalytically more active.

Preparation of Pt-complexes using similar and other ligands used are now under consideration and detailed studies will be published elsewhere [25].

\section{Preparation and spectroscopic studies of the complexes}

Schiff base ligands were prepared by condensation of amines with appropriate amounts of aldehydes. The complexes were prepared by mixing an alkaline alcoholic solution of the ligand with a solution of ferric chloride, dissolved in the same solvent. The mixture was refluxed for about $2 \mathrm{~h}$ on a water bath. The compounds obtained were filtered off, washed with ethanol and dried. The composition of the complexes, prepared in the molar ratio (1:1) (metal: ligand) can be represented as $\mathrm{FeCl}_{2} \cdot n \mathrm{H}_{2} \mathrm{O}$. To prepare binuclear complexes, i.e. in the molar ratio $(2: 1)$ (metal : ligand), some excess of metal ion and at least a solution of $2 \mathrm{M} \mathrm{NaOH}$ must be added, as confirmed from the analysis of the solid complexes.

On examining the i.r. spectra of the complexes it was found [26] that, in the mononuclear complexes the Schiff bases behave as tetradentate dibasic acids towards the ferric ion, i.e. the two nitrogen atoms and two oxygen atoms contribute to complex formation which can be represented as follows:

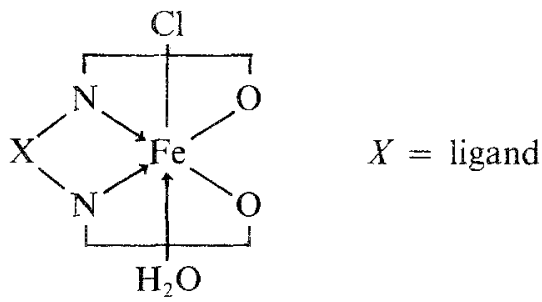

For other mononuclear complexes, it was found [26] that the ligand functions as a bidentate monobasic acid as follows:<smiles>O=CN(CCO)[P+]([O-])(O)Cl</smiles>

Also, the i.r. spectra of the binuclear $\mathrm{Fe}^{3+}$-complexes give the following structure:

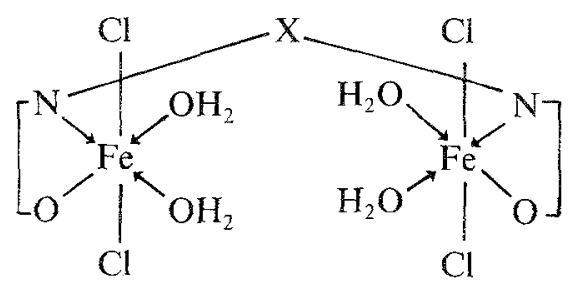

where $X=$ ligands.

The electronic absorption spectra revealed [23] that the position of the bands can account for the octahedral arrangement of the ligands around the $\mathrm{Fe}^{3+}$-ions. More details concerning the structure, and spectroscopic studies of the complexes, are given elsewhere [26]. 


\section{Conclusions}

The most extensively studied chelates as oxygenreduction catalysts are transition metal phthalocyanines (MePc), tetrasubstituted porphyrins (MeTRP) and dihydrodibenzotetraazaannulenes (MeTAA). It was found [11] that from the $3 \mathrm{~d}$ transition metals, the $\mathrm{N}_{4}$-chelates of $\mathrm{Fe}$ and Co exhibit the highest activity. With respect to the macrocyclic structure, TAA shows the highest activity, followed by Pc and TRP. In the present study, new results for some Fe-complexes are demonstrated. Such complexes have either mono- or binuclear Fe-Centres, and the structure of the ligands used are quite different. The adsorption of oxygen is explained by the formation of a $\sigma$-bond between a lone pair of the oxygen molecule and the empty $3 \mathrm{~d}_{z} 2$ orbital, and back-bonding due to overlap of an empty $\pi^{*}$ antibonding orbital of oxygen with a filled $3 \mathrm{~d}_{x z}$-or $3 \mathrm{~d}_{y z}$-orbital. The strongest interaction is therefore obtained, with $\mathrm{Fe}(\mathrm{II})$.

Different ligands change the location of the energy levels of the $3 \mathrm{~d}$ orbitals, e.g. with TAA the highest overlap between the $3 \mathrm{~d}$-orbitals of the central metal ion and the molecular orbitals of oxygen is obtained. With respect to the mechanism of oxygen-reduction, most authors assume that the rate determining step is the formation of superoxide $[27,28]$ :

$$
\mathrm{O}_{2}+e^{-} \longrightarrow \mathrm{O}_{2}^{-}
$$

which is $\mathrm{pH}$-independent. Generally, depending on the specific properties, as well as the selectivity of the catalyst, $\mathrm{O}_{2}^{-}$may directly be reduced to $\mathrm{H}_{2} \mathrm{O}_{2}$ or to $\mathrm{H}_{2} \mathrm{O}$ as a stable end product. The selectivity, is determined by the way the oxygen is adsorbed onto the catalyst [29]. If the $\mathrm{O}_{2}$-molecule interacts with only one metal atom (end-on or side-on adsorption), then $\mathrm{H}_{2} \mathrm{O}_{2}$ may be produced. On the other hand, if the $\mathrm{O}_{2}$ molecule is adsorbed at two metal atoms (bridge adsorption), direct $4 e^{-}$-reduction to $\mathrm{H}_{2} \mathrm{O}$ becomes possible. The previously discussed results for the Fe-complexes used fulfill both cases $\left(\mathrm{H}_{2} \mathrm{O}\right.$ and $\mathrm{H}_{2} \mathrm{O}_{2}$ formation) in acid and alkaline solutions.

For the application of transition metal chelates in fuel-cell electrodes good stability is of prime importance. The Fe-complexes used in this study have high stability: on repeating the measurements, i.e. either $\mathrm{CV}$ or $\mathrm{O}_{2}^{-}$reduction profiles after leaving the electrodes $\sim 24 \mathrm{~h}$ in the electrolyte solution and also after several scanning cycles, the same results were obtained.
Even the $E_{1 / 2}$-values, as well as the enhancement of the current levels, were increased.

\section{References}

[1] W. E. O'Grady, P. N. Ross and F. G. Will, Proc. Symp. Electrocatalysis, Vol. 82, Electrochemical Society (1982).

[2] E. Yeager, $\mathrm{O}_{2}$-electrocatalysis and the role of adsorbed intermediates, 31st ISE Meeting, Ext. Abstr. Vol. 1, Venice, Italy (1980) p. 131.

[3] J. Zagal, P. Bindra and E. Yeager, J. Electrochem. Soc. 127 (1980) 1506.

[4] R. A. Bull, F. R. Fan and A. J. Bard, ibid. 131 (1984) 687.

[5] M. I. Florit, W. E. O'Grady, C. A. Linkous, T. Skotheim and $\mathrm{M}$. Rosenthal, Abstract $\mathrm{N}$ 415, Ext. Abstr. Vol. 84.1, The Electrochemical Society (1984).

[6] A. Elzing, A. van der Putten, W. Visscher and E. Barendrecht, J. Electroanal. Chem. 200 (1986) 313.

[7] J. H. Zagal-Moya, Thesis, Case Western Reserve University, Cleveland (1978).

[8] A. van der Putten, A. Elzing, W. Visscher and E. Barendrecht, J. Chem. Soc. Chem. Commun. 1596 (1986) 477.

[9] B. Z. Nikolic, R. R. Adzic and E. B. Yeager, J. Electroanal. Chem. 103 (1979) 281-7.

[10] A. Elzing, A. van der Putten, W. Visscher and E. Barendrecht, to be published.

[11] H. Jahnke, M. Schönborn and G. Zimmermann, Top. Curr. Chem. 61 (1976) 133.

[12] L. Pauling, Nature 203 (1964) 182

[13] D. M. Mingos, ibid. 230 (1971) 154.

[14] E. I. Ochiai, J. Inorg. Nucl. Chem. 35 (1974) 3375.

[15] B. Hoffman, D. Diemente and F. Basolo, J. Amer. Chem. Soc. 92 (1970) 61.

[16] J. J. Weiss, Nature 203 (1964) 183.

[17] F. F. Ochiai, J. Inorg. Chem. 36 (1974) 2129

[18] J. P. Collman, M. Marocco, P. Denisevich, C. Koval and F. C. Anson, J. Electroanal. Chem. 101 (1979) 117.

[19] J. P. Collman, P. Denisevich, Y. Konai, M. Marocco, C. Koval and F. C. Anson, J. Amer. Chem. Soc. 102 (1980) 6027.

[20] R. R. Durand Jr., C. S. Bencosme, J. P. Collman and F. C. Anson, ibid. 105 (1983) 2710.

[21] S. Sarangapani, Ph.D. Thesis, Case Western Reserve University, Cleveland, OH (1983).

[22] E. Yeager, Mechanism of electrochemical reactions or nonmetallic surfaces, in 'Electrocatalysis on Non-metallic Surfaces', NBS Special Publication 455 (1976) pp. 203-19.

[23] M. Tarasevich, A. Sadkowski and E. Yeager, Oxygen Electrochemistry, in 'Comprehensive Treatise of Electrochemistry', Vol. 7, 'Kinetics and Mechanisms of Electrode Processes' (edited by B. Conway, J. Bockris, E. Yeager, S., Khan and R. White) Plenum Press, New York (1983) Chap. 6, pp. 301-98.

[24] G. McLendon and A. E. Martell, Goord. Chem. Rev. 19 (1976) 1.

[25] M. A. Elmorsi, to be published.

[26] K. Y. Fahmi, Ph.D. Thesis, Tanta University, Faculty of Science, Egypt (1987).

[27] D. T. Sawyer and E. T. Seo, Inorg. Chem. 16 (1977) 499.

[28] E. Yeager, Electrochim. Acta, 29 (1984) 1527.

[29] P. Fischer and J. Heitbaum, J. Electroanal. Chem. 112 (1980) 231. 